\title{
Integrating Extensive Reading in a College Preparatory Year Program: Perceptions, Challenges, and Possibilities
}

\author{
Joel C. Meniado \\ Yanbu English Language Institute \\ The Royal Commission for Jubail and Yanbu \\ Yanbu, Saudi Arabia \\ Tel: +966 (0)54-660-1526Ｅ-mail: meniadoj@rcyci.edu.sa
}

Received: August 5, 2018 Accepted: September 5, 2018 Published: September 9, 2018

doi:10.5296/ijele.v6i2.13624 URL: https://doi.org/10.5296/ijele.v6i2.13624

\begin{abstract}
Many studies in different EFL contexts have shown positive impacts of extensive reading (ER) on learners' language abilities, reading proficiency, motivation, and attitude toward reading. With the aim of investigating the appropriateness and effectiveness of ER in a context where there is no strong culture for reading, this study surveyed students' attitudes towards ER, their perceptions on the benefits they gain from ER, and the challenges they encountered during its implementation. Utilizing interview, it also examined teachers' perspectives on the possibilities and trajectories of ER within the institution after its first implementation. The study sample consisted of 365 randomly selected male Saudi college-level EFL students who answered the questionnaire and 5 teachers who separately responded to the unstructured interview. Results revealed that students have positive attitudes towards ER. They believe that ER is very useful, interesting, enriching, and empowering that it can make them better readers and learners. Results also revealed that ER provides various linguistic benefits. However, there can be challenges such as time constraints, lack of resources, and linguistic and cultural barriers. Analysis of the interview with teachers revealed that there can be many possibilities to improve ER implementation. The study concluded with its limitations and important recommendations.
\end{abstract}

Keywords: Extensive Reading, Reading Education, Teaching Reading 


\section{Introduction}

Improving students' poor reading skills is one of the major challenges faced by English language teachers in Saudi Arabia. As reflected in the results of high stakes English proficiency tests, Saudi students struggle in reading comprehension (Meniado, 2016). This phenomenon can be attributed to Saudi EFL learners' lack of essential reading habits in their first (L1) and second language (L2), rare use of the required reading skills and strategies when reading English texts, less exposure to the English language, limited opportunities to develop and exhibit comprehension, lack of motivation to read, dislike for reading topics in their textbooks, limited vocabulary, lack of training on reading strategies, and lack of support from parents and teachers (Al-Qahtani, 2016). Hence, teachers really need to adopt an approach where students are extensively and pleasurably engaged in reading, so they will develop essential reading habits that will make them proficient and passionate readers.

One of the widely used approaches designed to improve reading proficiency of students in many ESL and EFL contexts worldwide is the Extensive Reading (ER) program. It is an approach where students read large amount of texts "to develop good reading habits, to build up knowledge of vocabulary and structure, and to encourage a liking for reading" (Richard \& Schmidt, 2002, pp. 193-194). It is also an environment where readers enjoy reading wide array of self-selected, simplified texts written in a foreign language (Day \& Bamford, 1998; Renandya, 2007; Milliner, 2016). Lastly, it is a situation where readers voluntarily and silently read at a fast pace without performing any productive linguistic task thereafter (Hafiz \& Tudor, 1989).

For the past decades, several studies in different contexts have proven the effectiveness of ER in developing learners' language abilities in various aspects. Many researches claim that ER has positive impact on learners' general language proficiency, macro-linguistic skills development, and vocabulary knowledge (Al-Homoud \& Schmitt, 2009; Chien \& Yu, 2015). It also develops learner autonomy and general world knowledge, offers comprehensible input, extends and sustains vocabulary growth, and improves writing skill (Maley, 2009). In addition, it immerses students with the target language, helps them consolidate previously learned language, builds their confidence in dealing with extended texts, and enhances their comprehension skills (Bell, 1998). Lastly, it can help learners improve their motivation to read, attitude toward reading, and confidence to read (Al-Homoud \& Schmitt, 2009; Yamashita, 2013; Ro, 2013; Chien \& Yu, 2015; Salameh, 2017).

While ER is successful in various contexts, it is also a failure in some places due to the following reasons. First, establishing and sustaining a library of graded readers for extensive reading is expensive (Day \& Bamford, 1998; Hinkleman, 2013). A school needs to invest a fortune to procure needed books that are interesting and appropriate to learners' reading levels. Second, making students accountable for their reading can be difficult (Campbell \& Weatherford, 2013; Robb \& Kano, 2013). Due to teachers' demanding work, they can hardly find time to confirm whether students have really read the book or not. Third, ER is not a part of the language curriculum (Cote \& Milliner, 2015). Having it isolated from curriculum and examination makes teachers and students not to take it seriously. Fourth, teachers are too 
busy that they do not have time to track students' progress and to give feedback or assistance (Cote \& Milliner, 2015). Fifth, teachers view ER as a waste of time. Since they lack understanding of ER with its benefits, they maintain negative attitudes towards it. Lastly, teachers are pressured to strictly follow the syllabi and textbooks (Maley, 2009), so they tend to veer away from implementing the program or encouraging their students to read outside the classroom.

In Saudi Arabia, some colleges and universities have adopted Extensive Reading (ER) program using their own specific models that fit their own contexts in order to help students improve their overall English language proficiency in general and reading proficiency in particular. Some tertiary institutions implemented ER in their preparatory (foundation) year program, while others integrated it in their associate and bachelors programs (i.e. ESP, academic writing, etc.). In this study, the ER was integrated in the preparatory year program as requirement of the two (2) General English courses. As requirement, it is a part of the overall course assessment scheme. In other words, students are directed to read for some rewards with the assumption that as students read books or stories of their own liking, they will be able to gradually develop their proficiency and passion for reading.

However, in a culture where free voluntary reading is not a part of daily routine, will ER integration be successful? Will students appreciate the idea of reading English books / stories which are not part of their daily lives? Will teachers take the approach as a solution or another burden? While ER in other contexts (i.e. Japan, Korea, Taiwan, China, Mexico, etc.) is found to be effective in improving the general language proficiency, vocabulary and grammar skills as well as the proficiency and attitudes of ESL/EFL students towards reading, will the same finding be revealed in this current study's setting with students generally observed to have weak culture for reading? Will government-subsidized college students (subjects of this study) who are generally noted to have low motivation and grit find ER as another course component interesting? With the aim of exploring whether or not ER is an appropriate, effective, and transformative approach in making Saudi college students become proficient and passionate readers, this study specifically investigated the following:

1. What are the attitudes of the respondents towards extensive reading?

2. What are the benefits of extensive reading as perceived by the respondents?

3. What are the challenges encountered by the respondents during the first institution-wide implementation of extensive reading?

4. What are the possibilities and trajectories of extensive reading within the institution after its first implementation?

As results of studies on effectiveness of extensive reading are inconsistent (Al-Nafisah, 2015), it is important that an independent study in a particular context be conducted. Findings vary depending on the research methodology, respondents, and environment. In Saudi Arabia, few empirical studies on ER have been conducted within university settings where standard of student intakes is perceived to be higher than the setting of the current study. Aside from the level of students, these previously conducted studies also utilized different curricula and 
resources. With these variations, it is assumed that this study will yield unique results that can either support or contradict findings of previous researches.

While this study utilized only simple survey and interview with student and teacher respondents in a particular semester, it is still deemed significantly valuable, as it will provide theoretical and empirical foundations on the adoption and maintenance of ER program in the institution where it is conducted. With its findings, it is hoped that the study can: 1) inform the management on how teachers and students perceive extensive reading as a mechanism to help improve overall language proficiency particularly in reading, hence appropriate decision can be made; 2) serve pertinent data needed in enriching the curriculum and in improving the assessment scheme by revealing the problems and difficulties encountered in the implementation of ER program; 3) help curriculum developers in improving or redesigning the ER model that can perfectly fit into the context of the College by suggesting ways on how to make the program better; 4) be a helpful resource for other learning institutions planning to embark on ER by revealing some obstacles that may arise along the way and by suggesting ways on how to surmount such challenges; 5) contribute new knowledge to the existing body of literature on extensive reading; and 6) help future researchers in the same context conduct a more thorough investigation along the same line of inquiry.

\section{Review of Related Literature}

\subsection{Impacts of Extensive Reading (ER) on Language Learning}

Several studies reveal that ER improves English language learners' overall language proficiency, world knowledge, reading comprehension, and attitudes toward reading. According to Day et al (2011), ER expands learners' vocabulary range and their understanding of words. It also helps learners become better readers, writers, speakers, and listeners of spoken English due to some ER activities involved in the program (Day et al, 2011). In addition, it also helps learners improve their reading speed, word attack skills, and reading techniques (Walker, 1997). Moreover, due to learners' exposure to the language system in the written texts, they will also gain better understanding of English grammar. Lastly, because of feeling a sense of learning and accomplishment every time learners finish reading a book or article, they develop positive motivation and attitude toward reading and learning English in general (Day et al, 2011). Indeed, ER helps students learn to read and gives opportunities to read to learn.

The abovementioned general findings are supported by some individual studies conducted in different contexts. In the study of Villas (2016), she found that ER program improved vocabulary knowledge, reading fluency, and general language competence of Thai university students. In a more specific quantitative study of Mermelstein (2014) examining the effects of ER on Taiwanese university students' reading levels, he found that ER coupled with student-centered teaching approach can improve EFL students' reading levels. Similarly, Robb \& Kano (2013) also conducted a large-scale study on the effectiveness of ER on reading comprehension of Japanese university students. They found that after implementation 
of additive ER, Japanese students showed significant gains in reading comprehension as evidenced by the results of reading tests / quizzes in the MoodleReader system.

Focusing on effects of ER on writing skill, Mermelstein (2015) conducted a subsequent study exploring the effectiveness of an enhanced ER program on the writing abilities of Asian EFL students. The study revealed that after receiving the enhanced ER treatment, the students showed significant gains and sizable effects on the content, organization, vocabulary, language use, mechanics, and fluency of their writing. In Iran, Kargar (2012) also examined the effectiveness of extensive reading project on low-level Iranian EFL university students' reading proficiency. Utilizing experimental method, he found that ER has a positive effect on the reading proficiency achievement of low-level EFL students, those who have difficulties in comprehending texts written in foreign language.

In Saudi Arabia, some studies have also been conducted proving the value and effectiveness of ER in various aspects of English language learning. For example, in the study of Al-Homoud \& Schmitt (2009) comparing the effects of extensive reading and intensive reading among relatively weak Saudi EFL students who do not have a habit for pleasure reading, it was found that ER is better than intensive reading (IR) approach. Aside from helping improve comprehension ability, reading speed, and vocabulary acquisition, the study also revealed that ER develops positive attitudes toward learning and reading. In another study, Al-Nafisah (2015) also explored the effect of ER program on the reading comprehension of Saudi EFL university students. Using experimental method, he found that ER has positive effect on EFL students' reading comprehension. In similar setting, Al-Mansour \& Al-Shorman (2014) also investigated the effect of ER on the writing performance of Saudi EFL university students. Using experimental method, the study indicated that ER positively influences learners' writing performance.

Focusing on another impact of ER to other aspects of language learning, Al-Homoud \& Alsalloum (2012) examined the effects of ER on vocabulary development and reading speed of Saudi EFL learners. Using experimental method, they found that ER enhances Saudi learners' breadth and depth of vocabulary knowledge and reading speed. Also, it transforms students' attitudes toward learning a new foreign language. Along the same line of inquiry, Al-Hammad (2009) also conducted a study exploring the impact of ER in L2 vocabulary acquisition of Saudi EFL university students. The study revealed that ER can improve vocabulary acquisition most especially when it is supplemented with vocabulary enhancement activities and that it can also promote positive attitude toward reading and vocabulary learning. Determining the worthiness of ER in higher studies, Abdellah (2013) conducted a study investigating the effectiveness of an ER program on developing selected intensive reading skills for English majors at the College of Education of a Saudi EFL university. Using experimental method, he found that ER positively affects students' skills in other nonfiction readings. Further, ER also improves reading motivation and skills in standard-based reading.

As reflected in the abovementioned studies, ER affects language learners ranging from linguistic to affective facets. The affective facet was further validated in the following studies. 
In the study of Tien (2015), attitudes and perceptions on ER were explored in a Taiwanese EFL higher education context. Using descriptive survey method, the study revealed that ER can significantly change attitudes of both teachers and students toward reading. They perceived ER as a good way to learn English due to the linguistic benefits it brought to the students. In another study, Chien \& Yu (2015) investigated the effects of ER on improving unmotivated learners' attitudes toward reading in English. Using descriptive survey method, the study revealed that ER can improve learners' attitudes toward English reading (cognitive aspect of attitude). Results validate previous findings that ER, whether in print or online platform, positively influences learners' attitudes toward reading. In South Korea, Jang, Kang, \& Kim (2015) also experimented on the effectiveness of English extensive reading on students' reading proficiency and motivation. They found that ER activities made Korean learners to have higher levels of intrinsic reading motivation. Meng (2009) previously reported the same finding stating that ER can gradually shift Chinese EFL students from learning-to-read orientation to a reading-to-learn framework resulting to higher motivation to read.

Still on the relationship between ER and motivation, Ro (2013) conducted a single case study to examine an adult reader's motivation and anxiety shift towards L2 reading. The study revealed that ER could reduce anxiety while enhancing motivation towards L2 reading. According to the study, ER can boost confidence, comfort or ease, and enjoyment in second language reading. In Saudi Arabia, Salameh (2017) also investigated the effect of ER on Saudi EFL university students' reading attitudes. He found that ER could transform students' negative attitudes to positive attitudes toward reading. The study suggests that ER can be a valuable tool to develop a culture of reading in a community where there are unmotivated readers. Aside from motivation and positive attitude, ER could also develop learner autonomy.

While most studies prove the positive impact of ER on different aspects of language learning, a few found otherwise. For example, in the study of Shen (2008), it was found that ER did not greatly transform students' language proficiency, reading attitudes, and reading habits due to some identified factors. The study suggests that ER may have different impact depending on the design of the approach, the materials used, and the existing proficiency levels and attitudes of students and teachers toward ER. Rahmany, Zerei, \& Gilak (2013) also tried to investigate the effectiveness of ER on Iranian EFL learners' motivation for speaking. Results indicated that ER did not have a significant effect on the respondents' motivation for speaking. The same is true when Kirin (2010) conducted the same area of research focusing on writing ability. She found that ER did not improve EFL students' writing ability despite additional reading involvement and activities.

\subsection{Challenges in Extensive Reading Integration}

Implementing Extensive Reading program goes through a number of challenges and difficulties. For example, in Taiwan, it was found that students did not engage heavily with ER due to the heavy workload from tests, homework, and other school activities (Huang, 2015). Further, students found ER time-consuming and inefficient enough to boost their exam 
scores. In a prior study conducted in Hong Kong, Green (2005) revealed some issues and challenges faced in ER implementation. There was massive teachers' resistance in implementing ER due to overburden, exhaustion, and lack of training. ER was also taken as stand-alone component of the curriculum. Consequently, it was not taken seriously by students. In a separate study, Chien \& Yu (2015) reported some issues affecting the attitudes of stakeholders toward ER implementation. First is the adoption of simplified texts (Graded Readers) over real-world texts making vocabulary learning limited and superficial. Second is the costly investment needed in running an efficient and effective ER program. Last is the "lack of instruction and practice of the language features in texts, restraining the development of students' linguistic knowledge of the target language" (Chien \& Yu, 2015, pp. 2-3).

In Japanese context, Milliner \& Cote (2014) outlined three common problems encountered by schools and teachers in ER implementation. First is the expensiveness of building and sustaining a graded reader library. Graded Readers (Language Learner Literatures) is the backbone of successful ER program. Without such resources, it is impossible to implement an ER; however, they are costly, most especially to small schools. Second is the issue of ensuring accountability. Teachers need to make sure that students have really read the book they claim they have read. Requiring every student in a class of 30 to read at least one book per week for the span of 15 weeks would be challenging for teachers to determine students' full understanding of the text. Last is finding time to monitor the ER component and give feedback to every student, especially if reading is done at home. These issues confront teachers that may obstruct their willingness and passion to implement ER.

In Saudi Arabia, Al-Nafisah (2015) also identified some challenges encountered in ER implementation in Saudi classrooms. First is the non-existence of a solid reading culture in the Saudi society. Second is the non-emphasis of ER in English teaching syllabuses. Last is the lack of recognition or training of English teachers on how to implement ER in their classrooms. For teachers who are planning to implement ER in their classes, often they struggle in deciding on: 1) the time and place for student reading; 2) types of literatures to be purchased; 3) students' use of dictionary while reading; 4) placing students into the appropriate reading level / book level; 4) ways to inculcate the value of ER to students; 5) means to ensure accountability among students; and 6) the activities that can be implemented to help students achieve the goals of ER (Domenica, 2010).

With all the abovementioned challenges and difficulties, it is apparent that ER implementation is no easy task. As Malley (2012) summarized in his article, ER is rarely used because of: 1) insufficient time; 2) costliness; 3) unavailability of reading materials (graded readers); 4) non-integration in the curriculum and assessment; 5) lack of understanding on the value of ER; 6) downward pressure on teachers to follow strictly the syllabus and textbooks; 7) negative attitudes toward ER; 8) non-reader issue; and 9) the internet culture of the millennial.

\subsection{Trends and Possibilities in Extensive Reading}

To address the abovementioned issues in the implementation of ER in different contexts, different technological innovations have been introduced. The Moodle Reader, a free 
(learning management) system available online carrying a vast collection of graded readers, is now available for students where they can choose books of their own liking and read at their own pace, anywhere, anytime. After reading a graded reader, a student can take a quiz about its content and a feedback is automatically provided. Scores of students are kept in the database, which can then be accessed by both teachers and students. The interface of the system shows the cover of the book/s for which the quiz was successfully passed followed by the words the student has read and the points he has gathered (Robb in Day et al, 2011). In the study of Campbell (2012), he found that students perceived Moodle Reader as enjoyable and beneficial. Teachers also found the system a great help in lessening the burden of their job.

Another innovation created to make extensive reading implementation easier and more enjoyable for both teachers and students is the XReading. It is a combination of an online, virtual library containing hundreds of graded readers and a learner management system (LMS) devoted exclusively for ER purposes (Milliner \& Cote, 2014). It allows teachers to monitor and assess their students' reading behaviors, performances, and individual progress. Aside from giving immediate feedbacks, it helps them guide and motivate students to read based on their performance and preferences. Available in PC and mobile device, it allows students to access any book of their preference anywhere, anytime. It provides them more privileges in borrowing graded readers and gives them access to teacher's feedbacks on their reading performance and individual progress. According to the study of Cote \& Milliner (2015), they found that using XReading can change students' preferences in reading platform from paperback to online book. Further, XReading can give students more flexibility on time, place, and frequency of reading. On language learning outcomes, they found that ER through XReading increased students' reading speed, motivation to read, and reading performance.

Alongside technological trends influencing ER, possibilities continuously emerge that might shape the practice of ER in the future. Day (2015) envisioned what lies ahead at the ER practices. According to him, the current practices of supervised (or instructed) ER will continue in several forms (i.e. pure ER to fringe ER). The emergence of independent (noninstructed) ER, the involvement or engagement of individuals into ER without supervision, will also take shape in the years ahead. Lastly, the blended extensive and intensive reading will take a path in some schools due to the inclusion of ER units with graded readers excerpts in some course books which normally apply intensive reading approach. With the recent changes and developments in the implementation of ER, it is apparent that there are still many possibilities in the pipeline that could make it more efficient and effective in varying contexts.

\section{Method}

\subsection{Research Design}

This study utilized the mixed methods research design where both quantitative and qualitative data were combined to draw deeper interpretations and provide better understanding of the 
research problem (Crosswell, 2015). The quantitative data on the attitudes of the respondents towards extensive reading, its perceived benefits, and challenges and difficulties encountered were gathered through descriptive survey method while the qualitative data on some possible trends and trajectories of ER implementation in the subject institution were gathered through unstructured interview. According to Lodico, Spaulding, \& Voegtle (2010), the descriptive survey method is appropriate when the study aims to describe attitudes or gather opinions, beliefs, behaviors, or perceptions of a large group of people about current trends or issues. Unstructured interview, on the other hand, can be a helpful method when a study aims to explore deeper understanding of a phenomenon by focusing on people's actual experiences more than beliefs and opinions (King \& Harrocks, 2010).

\subsection{Sample}

The student-respondents of the study were 365 randomly selected male Saudi college-level EFL students. Spread in different sections, they were all at the same English proficiency level (Beginner Level, A1 in the CEFR Framework) taking up ENG 001 (General English), the introductory English course offered in the Preparatory Year Program of an all-male government college in Saudi Arabia. Considering logistics and time constraints, a random sampling technique was utilized in selecting student-respondents from 22 sections. To bridge the gap between logistics and reliability issues, the researcher decided to take fifty percent $(50 \%)$ of the total population as minimum sample requirement. The teacher-respondents in the unstructured interview were 5 teachers teaching ENG 001 course. Due to their active involvement in the planning, implementation, and evaluation of the institution-wide ER program, they were selected purposively with the assumption that they can give meaningful insights on possibilities and future of ER within the institution based on their knowledge and actual experiences.

\subsection{Instrument}

To answer the questions what are the attitudes of the respondents towards extensive reading?, what are the benefits of extensive reading as perceived by the respondents?, and what are the challenges encountered by the respondents during the first institution-wide implementation of extensive reading program?, a researcher-made survey questionnaire was conducted. The questionnaire is composed of 22 items categorized into three: a) attitudes on extensive reading; b) linguistic gains from extensive reading program; and c) problems and difficulties encountered during the implementation of the extensive reading program. Scaled from 1 to 5 , 5 being the highest and 1 being the lowest, each item is designed to elicit respondent's extent of agreement or disagreement on a particular statement about extensive reading. To ensure validity and reliability of the instrument, each survey item was constructed based on the research questions under investigation. Reading experts and course teachers were consulted to gather feedbacks on the content and appropriateness of the questions. Prior to the administration of the questionnaire, a try out was also conducted to a separate group of students who were not taking ENG 001 course. After receiving feedbacks and administration of the try out, necessary revisions in the questionnaire were made. To answer the last question what are the possibilities and trajectories of extensive reading within the institution after its 
maiden implementation?, unstructured interviews with selected teachers were conducted where feedbacks and insights on the institution-wide implementation of ER as well as recommendations for improvement were analyzed to set possible directions of the ER program within the institution.

\subsection{Data Collection}

The gathering procedure for the quantitative data started with seeking permission from the manager of the English Language Center. After securing approval to conduct the survey, the researcher asked help from his co-teachers to float the questionnaires in their respective sections. Upon acceptance, the survey on extensive reading program was administered to randomly selected students in their respective sections. Since the teachers in their respective classrooms supervised the conduct of the survey, questions or clarifications from the respondents were entertained; hence the truthfulness and genuineness of the responses were ensured. Further, since teachers personally administered the questionnaires during their class sessions, the percentage of retrieval was $100 \%$.

The qualitative data of the study were collected from the teacher respondents. After seeking approval from the Center management, the researcher scheduled a one-to-one interview with the selected teachers. During the unstructured interview, teachers were asked on their overall experiences during the implementation of the ER program. Specifically, they were asked on the challenges they encountered and possible mechanisms and activities that can make the program more interesting and beneficial to the students. The responses were coded, categorized, and summarized into themes.

\subsection{Data Analysis}

The quantitative data on respondents' perceptions towards extensive reading, linguistic gains from extensive reading program, and the problems and difficulties encountered during the ER implementation were analyzed using a 5-point Likert Scale, Weighted Mean, and Ranking. The qualitative data on the other hand were analyzed using common themes and categories that can help answer the problem under investigation.

\section{Results}

\subsection{What are the attitudes of the respondents towards extensive reading?}

Table 1. Attitudes on extensive reading

\begin{tabular}{llll}
\hline Items & Mean & QD & Rank \\
\hline $\begin{array}{l}\text { 1. Reading English books (stories/novels) everyday is } \\
\quad\end{array}$ & 3.99 & A & 4 \\
$\begin{array}{l}\text { very useful. } \\
\text { 2. Reading outside the class (i.e. home, library, park, } \\
\quad \text { etc.) is personally rewarding. }\end{array}$ & 4.00 & A & 3 \\
$\begin{array}{l}\text { 3. Students should be strongly encouraged to read } \\
\text { more than the required readings in class. }\end{array}$ & 3.50 & A & 8
\end{tabular}


4. Reading is more enjoyable if I can choose what I want to read.

5. I mainly read for pleasure, so I find extensive reading interesting and enjoyable.

6. Extensive reading allows me to engage with different reading materials and activities.

7. Extensive reading provides me variety and flexibility in reading.

8. Extensive reading helps me become more motivated to read.

9. Extensive reading helps me become a better reader.

10. Extensive reading can help me improve my communication skills in English.

$\begin{array}{lll}4.34 & \mathrm{SA} & 1 \\ 3.25 & \mathrm{~N} & 9 \\ 3.72 & \mathrm{~A} & 6 \\ 3.65 & \mathrm{~A} & 7 \\ & & \\ 3.23 & \mathrm{~N} & 10 \\ & & \\ 4.16 & \mathrm{~A} & 2 \\ 3.86 & \mathrm{~A} & 5 \\ & & \end{array}$

\section{$3.77 \quad$ A}

Table 1 shows the attitudes or beliefs of the respondents towards extensive reading with the corresponding weighted mean scores and qualitative descriptions. As reflected, the respondents strongly agree that extensive reading is more enjoyable if they can choose what they want to read (4.34). They also agree that ER helps them become better reader (4.16) and that it rewards them personally (4.00). Further, they agree that reading English books everyday is very useful (3.99) and can help them improve their communication skills in English (3.86). Moreover, they also agree that ER allows them to engage with different reading materials and activities (3.72), provides them variety and flexibility in reading (3.65); thus they should be strongly encouraged to read more than the required reading in class (3.50). While they agree to most of the items, they remain neutral on claims stating they find ER interesting and enjoyable (3.25) and that it helps them become more motivated to read (3.23). In general, the respondents have positive attitudes toward extensive reading as reflected by the overall weighted average mean score of 3.77 .

\subsection{What are the benefits of extensive reading as perceived by the respondents?}

Table 2. Linguistic gains from extensive reading program

\begin{tabular}{|c|c|c|c|}
\hline Items & Mean & QD & Rank \\
\hline $\begin{array}{l}\text { 1. I feel Extensive Reading improved my reading } \\
\text { proficiency. }\end{array}$ & 4.30 & $\mathrm{SA}$ & 2 \\
\hline 2. I feel Extensive Reading improved my speaking skill. & 4.05 & A & 4 \\
\hline 3. I feel Extensive Reading developed my vocabulary. & 4.29 & SA & 3 \\
\hline 4. I feel Extensive Reading improved my reading speed. & 4.32 & SA & 1 \\
\hline \multirow[t]{2}{*}{ 5. I feel Extensive Reading improved my writing skill. } & 3.73 & A & 5 \\
\hline & 4.14 & A & \\
\hline
\end{tabular}


Table 2 presents the perceived linguistic benefits the respondents gained from the English Language Center's extensive reading program. As reflected, the respondents strongly agree that the ER program improved their reading speed (4.32), reading proficiency (4.30), and vocabulary skill (4.29). They also agree that the ER program improved their speaking skill (4.05) and writing skill (3.73). In general, the respondents agree that ER helped them improve many aspects of their English language learning, as manifested by the overall weighted mean average score of 4.14 .

4.3 What are the challenges encountered by the respondents during the first institution-wide implementation of extensive reading program?

Table 3. Problems and difficulties encountered

\begin{tabular}{llll}
\hline Items & Mean & QD & Rank \\
\hline 1. Lack of available books to choose from & 3.09 & Moderate & 2 \\
2. Lack of monitoring and support from teachers & 2.77 & Moderate & 5 \\
3. Lack of time to read & 3.18 & Moderate & 1 \\
4. Inability to comprehend & 3.04 & Moderate & 3 \\
5. Lack of conducive places for silent reading & 2.88 & Moderate & 4 \\
\hline
\end{tabular}

Table 3 reveals the challenges encountered by the respondents during the implementation of the ER program. As shown above, lack of time to read is the primary struggle of the respondents (3.18), followed by lack of available books to choose from (3.09), inability to comprehend (3.04), lack of conducive places for silent reading (2.88), and lack of monitoring and support from teachers (2.77). The overall responses of the respondents register an average weighted mean score of 2.99 , which means the abovementioned problems are moderate.

4.4 What are the possibilities and trajectories of extensive reading within the institution after its maiden implementation?

Teacher-respondents, as deduced in the interview, perceive extensive reading as an enjoyable and beneficial tool for students to improve their overall English language proficiency and reading motivation. It is a useful mechanism to develop a culture of reading among the young. However, they had difficulty in providing sufficient storybooks appropriate to the students' culture and existing English proficiency. Also, they had difficulty in efficiently monitoring and ensuring that all students understood the book they read and did the required outputs themselves. Considering that there were 22 sections with 30 students in each, monitoring cheating was difficult. Also, the teachers found difficulty in giving weekly feedbacks to 
students on their weekly output submission, as they had to finish the course syllabus according to the pacing schedule. There was a time pressure put on the teachers alongside their heavy work schedule.

To address the abovementioned problems, the teacher-respondents recommended the English Language Center (ELC) to adopt a computerized or online system where students can find wide selection of graded readers / storybooks appropriate to their culture and language level and can take automatically scored questions to efficiently check their comprehension. This way, accountability among students is ensured and cases of cheating are lessened. To deeply instil a culture of reading among students, one to two hours per week should also be allotted in the syllabus / pacing schedule where students are given the time to read their storybooks in class, discuss with themselves different stories, and present their outputs. This ER hour can also be used by teachers to give feedbacks on students' outputs and reading progress. Lastly, an accessible ER library with print and non-print materials should be established within the ELC to provide more options and opportunities for students as well as teachers to read during their leisure time. ER should not only be confined to storybooks but also to other authentic texts which students are meaningfully exposed to in their everyday life.

\section{Discussion}

Based on the results of the survey, the respondents show positive attitude towards extensive reading. They believe that ER is very useful, interesting, enriching, and empowering. Further, they believe that ER can help them become better readers, learners, and communicators in their everyday lives. Reflecting positive results, this study supports previous findings that ER can develop positive motivation and attitude toward reading and learning English in general (Day et al., 2011; Al-Homoud \& Schmitt, 2009; Al-Hammad, 2009; Chien, 2015; Chien \& Yu, 2015; Jang, Kang, \& Kim, 2015; Meng, 2009). The findings also confirm the transformative and personal value of ER as it can boost confidence, comfort or ease, and enjoyment (Ro, 2013; Salameh, 2017). Lastly, results also show that ER can promote learner empowerment and autonomy, since they are given choices, variety, and flexibility during the whole duration of the program.

Results of this study also reveal various linguistic gains from ER. Respondents believe that ER has improved their reading proficiency, reading speed, speaking, vocabulary, and writing skills. These results support previous claims that ER can enhance vocabulary knowledge, reading fluency, and general language competence (Villas, 2014; Al-Homoud \& Schmitt, 2009; Al-Homoud \& Alsalloum, 2012; Al-Hammad, 2009) as well as reading proficiency (Kargar, 2012), reading levels and comprehension (Mermelstein, 2014; Robb \& Kano, 2013; Al-Nafisah, 2015), and writing fluency (Mermelstein, 2015; Al-Mansour \& Al-Shorman, 2014). The respondents in the study perceive improvements in their reading proficiency, reading speed, and vocabulary due to their engagement with different reading materials and other required outputs that demand reading. They also perceive developments in their writing and speaking as they had to submit written report summarizing the story they read and had to present the summary of the story in class using PowerPoint presentation and other visuals. 
While the ER program presents positive impacts and benefits, there are also some challenges attached to it. Primary to these challenges as perceived by the respondents is the lack of time to read. This same problem supports the findings of Huang (2015) and Malley (2012) claiming that students do not heavily engage with ER because of heavy workload from tests, homework and other school activities. According to Al-Nafisah (2015), Saudi students usually reason out having lack of time to read when given assignment to read because of non-existence of solid reading culture in the Saudi society. While they generally recognize the value of reading, they give reading less priority than their other daily activities.

Other problems faced were the students' inability to comprehend and lack of resources and facilities that support extensive reading. Since the ELC does not have well-established graded reader library, students borrowed storybooks from the college library or bought novel books from bookstore which were way above their existing language level, hence found difficulty in comprehending. This challenge is common in most schools because building and sustaining a graded reader library can be costly (Milliner \& Cote, 2014). Another problem faced by students is the lack of monitoring and support from teachers. Due to heavy workload of teachers doing teaching and para-teaching duties coupled with downward curriculum and assessment pressures, they can hardly find time to extend help beyond their teaching hours and efficiently give feedbacks to all students (Malley, 2012).

Interview with the teachers reveal their perceptions and perspectives toward extensive reading. While they recognize the value of ER, they all agree that there have to be some improvements in the second implementation of the ER program in order to make it more useful to the students. The current institution-wide practice of supervised (or instructed) ER, either in the form of pure ER or fringe ER, has to be maintained and refined. The refined model has to uphold the 10 principles of ER where learners read as much as possible, choose what they want to read, and are provided with a variety of reading material on a wide range of topics (Day, 2015).

To make ER more integrated into the curriculum, the blended extensive and intensive reading can also be adopted by the ELC. Some book publishers are now providing features available electronically or online some supplementary texts or excerpts of graded readers in addition to the main reading selections in each unit. These can be used as materials for extensive reading component of the course. Moreover, Internet resources can also be exploited by the Center for extensive reading purposes. For example, teachers can subscribe to Newsela (www.newsela.com) and CommonLit (www.commonlit.org) and register their students for free. Containing interesting, enjoyable, and appropriate reading materials and assessment tools, these free instructional content platforms can be used as powerful tool for ER. They unburden the school from establishing expensive graded readers library as well as the teachers in selecting appropriate texts, monitoring comprehension, and giving feedbacks.

In addition to free Internet ER platforms, the Center can also subscribe to Moodle Reader Module (http://moodlereader.org) and Xreading (http://xreading.com) to make ER more accessible to digitally wired young learners (Day, 2015). These platforms carry vast collection of online storybooks (graded readers) in different topics. Students can read books 
appropriate to their levels and interests, and then take automatically scored quizzes after. They have features of randomizing questions to prevent cheating; hence, accountability among students is ensured. They also carry learning management system (LMS) where teachers can monitor and assess students' reading behaviors, performances, and individual progress (Milliner \& Cote, 2014). With the advent of new technologies, ER also needs to change to make itself more relevant and valuable to all its stakeholders.

\section{Conclusion}

Findings of this study reveal that the respondents view extensive reading as a helpful tool to develop macro-linguistic skills, communication skills, and personality. Specifically, the respondents perceive that ER can improve reading proficiency, vocabulary, positive attitudes toward reading and learning English, motivation to read, and personal confidence. This welcoming attitude toward ER should be capitalized by both teachers and school administrators by refining the program suited to the context of the learners while upholding the basic principles of ER in order bring optimum results. While it is true that the respondents belong to a society where culture of reading does not exist (Nafisah, 2015), their positive attitudes toward ER can be a good starting point to develop a nation that reads. Developing a culture of reading through ER can be challenging due to lack of resources and support, but with strong commitment and creativity of teachers and administrators, problems may lead to opportunities or possibilities. This study has explored many possibilities for ER implementation. These innovative trends and practices should be adopted and integrated in the curriculum in order to make the program more responsive and transformative to young learners.

While the findings of this study can be useful in decision making in a specific educational context and in enriching literatures pertaining to extensive reading, it acknowledges its limitations in generalizability and reliability considering its scope, nature, methodology and sample size. The study dealt only with perceptions of limited number of respondents on the impacts of ER on their reading proficiency and language learning. An experimental research along this line of inquiry should be conducted to yield more reliable results.

\section{References}

Abdellah, Antar. (2013). Training Saudi English majors in extensive reading to develop their standard-based reading skills. Journal of King Saud University - Languages and Translation, 25, 13-20. http://dx.doi.org/10.1016/j.jksult.2012.12.002.

Al-Hammad, N. M. (2009). The role of extensive reading in L2 vocabulary acquisition: An empirical study on Saudi female students of the Department of English, King Saudi University (Unpublished masters thesis). King Saud University, Saudi Arabia.

Al-Homoud, F. A., \& Alsalloum, M. S. (2012). The effects of extensive reading on the breadth and depth of vocabulary knowledge and reading speed. Extensive Reading World 
Congress Proceedings, 1, 65-67. Retrieved from http://erfoundation.org/ proceedings/erwc1-AlHomoud-Alsalloum.pdf.

Al-Homoud, F. A., \& Schmitt, N. (2009). Extensive reading in a challenging environment: a comparison of extensive and intensive reading approaches in Saudi Arabia. Language Teaching Research, 13(4), 383-401. http://dx.doi.org/10.1177/ 1362168809341508.

Al-Mansour, N. S., \& Al-Shorman, R. A. (2014). The effect of an extensive reading program on the writing performance of Saudi EFL university students. International Journal of Linguistics, 6(2), 258-275. http://dx.doi.org/10.5296/ijl.v6i2.5551.

Al-Nafisah, K. I. (2015). The effectiveness of an extensive reading program in developing Saudi EFL university students' reading comprehension. Arab World English Journal, 6(2), 98-109. http://dx.doi.org/10.2139/ssrn.2834380.

Al-Qahtani, A. A. (2016). Why do Saudi EFL readers exhibit poor reading abilities? English Language and Literature Studies, 6(1), 1-15. http://dx.doi.org/10.5539/ells. v6n1p1.

Bell, T. (1998). Extensive reading: why? and how?. The Internet TESL Journal, 4(12). http://iteslj.org/Articles/Bell-Reading.html.

Campbell, A. P. (2012). Implementing the MoodleReader Module. Extensive Reading World Congress Proceedings, 1, 101-104. Retrieved from http://erfoundation.org/ proceedings/erwc1-Campbell.pdf.

Campbell, J., \& Weatherford, Y. (2013). Using M-Reader to motivate students to read. In S. Miles \& M. Brierley (Eds.), Extensive Reading World Congress Proceedings (pp. 1-12). Seoul: Extensive Reading Foundation. Retrieved from http://erfoundation.org /ERWC2-Proceedings.pdf.

Chien, C. C., \& Yu, K. (2015). Applying extensive reading to improve unmotivated learners' attitudes toward reading in English. International Journal of Learning, Teaching and Educational Research, 13(2), 1-25. https://www.ijlter.org/index.php/ ijlter/article/view/ 356/193.

Cote, T., \& Milliner, B. (2015). Implementing and managing online extensive reading: student performance and perceptions. IALLT Journal of Language Learning Technologies, 45(1), 70-90. https://ialltjournal.org/index.php/ialltjournal/article/view File/67/58

Crosswell, J. W. (2015). A concise introduction to mixed methods research. London: Sage Publications.

Day, R. (2015). Extending extensive reading. Reading in a Foreign Language, 27(2), 294-301. http://nflrc.hawaii.edu/rfl/October2015/discussions/day.pdf.

Day, R., \& Bamford, J. (1998). Extensive reading in the second language classroom. New York: Cambridge University Press.

Day, R., et al. (2011). Bringing extensive reading into the classroom. Oxford: Oxford University Press. 
Domenica, P. (2010). Extensive reading in the classroom. MA TESOL Collection. Paper 486. http://digitalcollections.sit.edu/cgi/viewcontent.cgi?article=1486\&context=ipp_collection.

Hafiz, F., \& Tudor, I. (1989). Extensive reading and development of language skills. English Language Teaching Journal, 43(1), 4-13. https://doi.org/10.1093/elt/43.1.4.

Huang, Y. C. (2015). Why don't they do it? A study on the implementation of extensive reading in Taiwan. Cogent Education, 2(1), 1099187. https://doi.org/10.1080/233 1186X.2015.1099187.

Hinkelman, D. (2013). Blending technologies in extensive reading: MoodleReader in a Japanese university EFL program. In S. Miles \& M. Brierley (Eds.), Extensive Reading World Congress Proceedings (pp. 91-100). Seoul: Extensive Reading Foundation. Retrieved from http://erfoundation.org/ERWC2-Proceedings.pdf.

Jang, H. H., Kang, M. K., \& Kim, Y. H. (2015). The effect of extensive reading activities on students' reading proficiency and reading motivation. Advanced Science and Technology Letters, 92(2015), 92-95. http://dx.doi.org/10.14257/astl.2015.92.19.

Kargar, A. A. (2012). The efficiency of extensive reading project (ERP) in an Iranian EFL context. Theory and Practice in Language Studies, 2(1), 165-169. http://dx.doi.org/10.4304/tpls.2.1.165-169.

King, N., \& Harrocks, C. (2010). Interviews in qualitative research. London: Sage Publications.

Kirin, W. (2010). Effects of extensive reading on students' writing ability in an EFL class. The Journal of Asia TEFL, 7(1), 285-308. www.asiatefl.org/main/download _pdf.php?i=190\&c=1419308557.

Lodico, M. G., Spaulding, D. T., \& Voegtle, K. H. (2010). Methods in educational research: From theory to practice ( $2^{\text {nd }}$ ed.). USA: Jossey-Bass.

Maley, A. (2009). Extensive reading: why it is good for our students... and for us. Retrieved from https://www.teachingenglish.org.uk/article/extensive-reading-why-it-good-ourstudents $\%$ E2\%80\%A6-us.

Meng, F. (2009). Developing students' reading ability through extensive reading. English Language Teaching, 2(2), 132-137. http://dx.doi.org/10.5539/elt.v2n2p132.

Meniado, J. C. (2016). Metacognitive Reading Strategies, Motivation, and Reading Comprehension Performance of Saudi EFL Students. English Language Teaching, 9(3), 118-129. http://dx.doi.org/10.5539/elt.v9n3p117.

Mermelstein, A. D. (2014). Improving EFL learners' reading levels through extensive reading. The Reading Matrix, 14(2), 227-242. http://www.readingmatrix.com/files/ 11-cmy65135.pdf.

Mermelstein, A. D. (2015). Improving EFL learners' writing through enhanced extensive reading. Reading in a Foreign Language, 27(2), 182-198. http://nflrc.hawaii.edu/rfl/ October2015/articles/mermelstein.pdf. 
Milliner, B. (2017). One year of extensive reading on smartphones: A report. JALLTCALL Journal, 13(1), 49-58. Retrieved from https://files.eric.ed.gov/fulltext /EJ1141027.pdf.

Milliner, B., \& Cote, T. (2014). Effective extensive reading management with Xreading. The Languge Teacher, 38(6), 32-34. Retrieved http://www.jalt-publications.org/tlt/ departments/tlt-wired/articles/4184-effective-extensive-reading-management-xreading.

Rahmany, R., Zarei, A. A., \& Gilak, S. (2013). The effect of extensive reading on Iranian EFL learners' motivation for speaking. Journal Language Teaching and Research, 4(6), 1238-1246. http://dx.doi.org/10.4304/j1tr.4.6.1238-1246

Renandya, W. A. (2007). The power of extensive reading. RELC Journal, 38(2), 133-149. http://dx.doi.org/10.1177/0033688207079578

Richard, J. C., \& Schmidt, R. (Eds.). 2002. Longman dictionary of language teaching and applied linguistics $\left(3^{\text {rd }} \mathrm{ed}\right)$. London: Longman.

Ro, E. (2013). A case study of extensive reading with an unmotivated L2 reader. Reading in a Foreign Language, 25(2), 212-233. http://nflrc.hawaii.edu/rfl/ October2013/articles/ro.pdf.

Robb, T. \& Kano, M. (2013). Effective extensive reading outside the classroom: A large-scale experiment. Reading in a Foreign Language, 25(2), 234-247. http://nflrc. hawaii.edu/rfl/October2013/articles/robb.pdf

Salameh, L. A. (2017). Investigating the effect of extensive reading on EFL learners' reading attitudes at Hail University in KSA. Journal of Education and Practice, 8(8), 7-15. http://www.iiste.org/Journals/index.php/JEP/article/view /36028/37022.

Shen, M.Y. (2008). EFL learners' responses to extensive reading: survey and pedagogical applications. The Reading Matrix, 8(2), 111-123. http://www.readingmatrix.com/ articles/shen/article.pdf.

Tien, C.Y. (2015). A large-Scale Study on Extensive Reading Program for Non- English Majors: Factors and Attitudes. International Journal of Applied Linguistics \& English Literature, 4(4), 46-54. http://dx.doi.org/10.7575/aiac.ijalel.v.4n.4p.46

Villas, M. (2016). Extensive reading: its effects to learners' general language competence. The Online Journal of New Horizons in Education, 6(4), 80-85. https://www.tojned.net/journals/tojned/articles/v06i04/v06i04-09.pdf

Walker, C. (1997). A self-access extensive reading project using graded readers (with particular reference to students of English for academic purposes). Reading in a Foreign Language, 11(1), 121-149. http://nflrc.hawaii.edu/rfl/PastIssues/rfl111 walker.pdf

Yamashita, J. (2013). Effects of extensive reading on reading attitudes in a foreign language. Reading in a Foreign Language, 25(2), 234-247. http://nflrc.hawaii.edu/ rfl/October2013/articles/yamashita.pdf. 


\section{Copyright Disclaimer}

Copyright for this article is retained by the author(s), with first publication rights granted to the journal.

This is an open-access article distributed under the terms and conditions of the Creative Commons Attribution license (http://creativecommons.org/licenses/by/3.0/). 